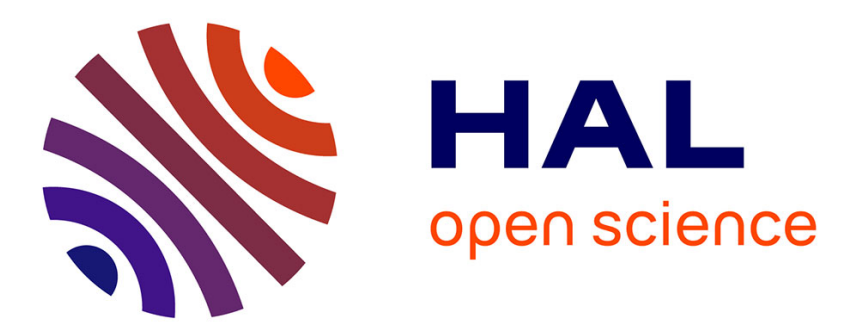

\title{
Mechanical and thermomechanical characterization of different leathers
}

N. Di Cesare, G. Corvec, X. Balandraud, Jean-Benoit Le Cam, J. Gauffreteau

\section{To cite this version:}

N. Di Cesare, G. Corvec, X. Balandraud, Jean-Benoit Le Cam, J. Gauffreteau. Mechanical and thermomechanical characterization of different leathers. 2018 Annual Conference on Experimental and Applied Mechanics, 2018, Paris, France. pp.63-68, 10.1007/978-3-319-95074-7_12 . hal-02161134

HAL Id: hal-02161134

https://hal-univ-rennes1.archives-ouvertes.fr/hal-02161134

Submitted on 7 May 2020

HAL is a multi-disciplinary open access archive for the deposit and dissemination of scientific research documents, whether they are published or not. The documents may come from teaching and research institutions in France or abroad, or from public or private research centers.
L'archive ouverte pluridisciplinaire HAL, est destinée au dépôt et à la diffusion de documents scientifiques de niveau recherche, publiés ou non, émanant des établissements d'enseignement et de recherche français ou étrangers, des laboratoires publics ou privés. 


\title{
Mechanical and Thermomechanical Characterization of Different Leathers
}

\author{
Noëlie Di Cesare, Guillaume Corvec, Xavier Balandraud, Jean-Benoît Le Cam, and Julien Gauffreteau
}

\begin{abstract}
Leather materials are able to undergo various strain and stress states during their elaboration process and their use in numerous applications. Although the experimental mechanical response in tension of leathers has been studied in the literature for decades, scarce information is available on the nature of their elasticity and more generally on their thermomechanical behaviors. In the present study, two leathers were tested under uniaxial cyclic loading while temperature changes were measured at the specimens' surface by infrared thermography. The heat power at the origin of the temperature changes was then determined by using an adequate version of heat diffusion equation which is applicable to homogeneous tests. Results enabled us to discuss on the physical nature of the thermoelastic coupling in leathers. Intrinsic dissipation caused by the mechanical irreversibility was also detected. Distinct behaviors are evidenced as a function of the type of leathers.
\end{abstract}

Keywords Infrared thermography · Leather · Heat source - Thermoelastic coupling · Mechanical dissipation

\subsection{Introduction}

Although the experimental mechanical response in tension of leathers has been studied in the literature for decades [1-5], scarce information is available on the nature of their elasticity and more generally on their thermomechanical behaviors. Some physical phenomena involved in their deformation mechanism have been proposed to model their mechanical response in terms of stiffness, rupture or relaxation. Beyond mechanical tests, some measurements carried out by using infrared (IR) thermography have been performed to analyze the temperature variations at the surface of leathers. Two types of approach are reported in the literature:

- application to non-destructive control of final leather products [6]. In this case, pulsed-phase thermography was performed to evidence hidden scratches and the texture in depth, and finally to evaluate the quality of the leather;

- analysis of the thermal response of leathers under mechanical loading [7-9]. More precisely, applications concerned the self-heating under cyclic loading, with the main objective of determining a limit of acceptable damage for leather products.

The present study belongs to the second type of approach and aims at studying the thermomechanical response of leathers under cyclic mechanical loading, more precisely under load-unload cycles. Due to thermomechanical couplings, any material produces or absorbs heat when stretched. In particular, thermoelastic couplings occur in any material. Two types of thermoelastic couplings can be distinguished: a "classical" thermoelastic coupling, which is sometimes named isentropic coupling [10] and occurs in metallic materials and polymers below their glass transition temperature; an entropic coupling, which occurs in rubber-like materials [11]. Rubber-like materials actually feature both types of thermoelastic coupling. Even though the entropic coupling is preponderant, the thermoelastic coupling occurs and is response for the

N. Di Cesare

Université Bretagne Sud, IUT de Lorient-Pontivy, IRDL, FRE CNRS 3744, Pontivy, France

G. Corvec · J.-B. Le Cam (ه)

Univ Rennes, CNRS, IPR (Institute de Physique de Rennes) - UMR 6251, Rennes, France

LC-DRIME, Joint Research Laboratory, Cooper Standard - Institut de Physique UMR 6251, Rennes Cedex, France

e-mail: jean-benoit.lecam@univ-rennes1.fr

X. Balandraud

Université Clermont Auvergne, CNRS, SIGMA Clermont, Institut Pascal, Clermont-Ferrand, France

J. Gauffreteau

SIGMA Clermont, Campus Design, Matériaux \& Innovation, Aubière Cedex, France 
thermoelastic inversion at low strains $[12,13]$. Any mechanical irreversibility occurring in a material is also accompanied by heat production: plasticity, fatigue damage and viscosity are all associated with a heat production leading to material self-heating, i.e. a global increase in temperature. Measuring temperature changes at the surface of tested specimens is thus relevant to improve our understanding of materials' behavior. However, the analysis of the heat sources provides more relevant information than the analysis of the temperature changes (By "heat source", we mean the heat power density in W/ $/ \mathrm{m}^{3}$ produced or absorbed by the material itself due to a change in the mechanical state). Indeed, temperature is affected by the heat diffusion in the specimen and with the outside of the specimen (by conduction with the jaws of the testing machine, by convection with ambient air) and by radiations. Therefore, heat source is a "more intrinsic" quantity for investigating damage and deformation mechanisms. The heat source fields are reconstructed from the temperature fields and the heat diffusion equation [14, 15]. A zero-dimensional (0D) version of this equation can be employed when heat sources are homogeneous in the specimen, typically when the strain fields are homogeneous. This approach was used for rubbers [16-22], shape-memory alloys [23-29], polyamide 6.6 [30-34], PMMA [35], aluminum alloy [36], steel [37], copper [35, 38]. To the best knowledge of the authors, heat source calculation has never been performed in case of leathers.

In the present study, two leathers were tested under uniaxial cyclic loading while temperature changes were measured at the specimens' surface by using IR thermography. The heat power density at the origin of the temperature changes was then determined using the $0 \mathrm{D}$ version of the heat diffusion equation to analyze the thermomechanical response of the tested leathers.

\subsection{Experimental Set-Up}

The experimental set-up is presented in Fig. 12.1. Tests were conducted with a uniaxial testing machine featuring two actuators. Specimens were cut in a split cow leather (L1) and a grain calf leather (L2). A sample made of the same material as that tested was also used as a reference in order to follow the variation in the close environment. It was therefore not stretched. The free length of both specimens was equal to $63 \mathrm{~mm}$. Tests were performed at ambient temperature. The loading consisted of load-unload cycles at a displacement rate of $\pm 100 \mathrm{~mm} / \mathrm{min}$. Two blocks of 6 cycles were successively applied. The maximum stretch was set to a quarter and a half of the stretch at failure for the first and second block, respectively.

Temperature measurements were performed by using a FLIR infrared camera equipped with a focal plane array of $640 \times 512$ pixels and detectors operating in wavelengths between 1.5 and $5.1 \mu \mathrm{m}$. The integration time was equal to $1000 \mu \mathrm{s}$ and the acquisition frequency was the same as for kinematic images, i.e. 25 fps. The thermal resolution or noise equivalent temperature difference is equal to $20 \mathrm{mK}$ for a temperature range between 5 and $40{ }^{\circ} \mathrm{C}$. The infrared camera was switched

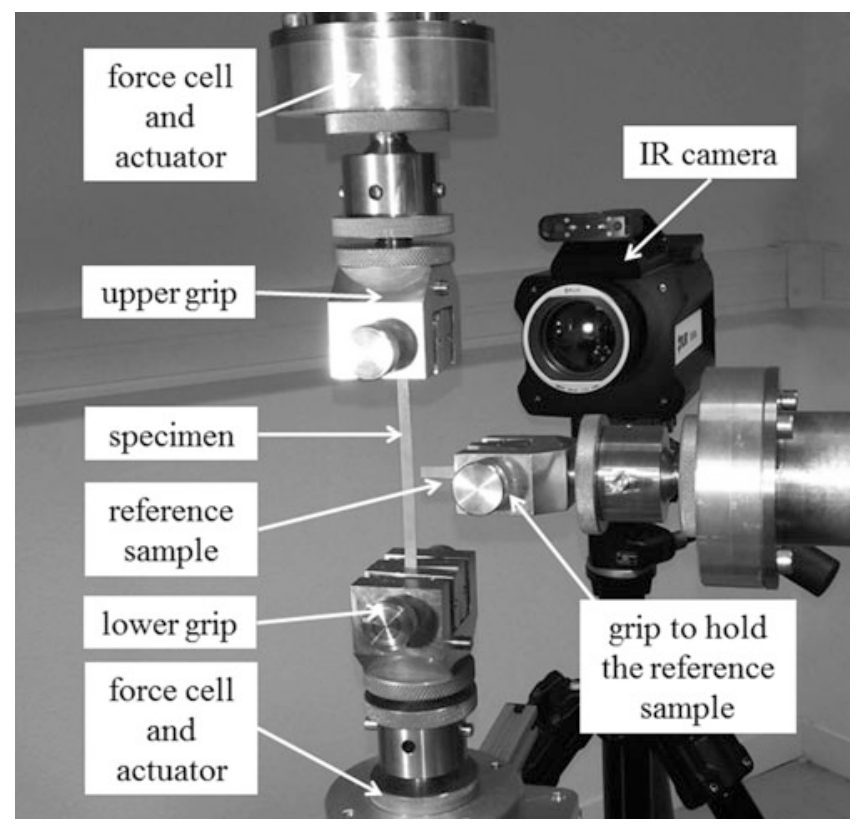

Fig. 12.1 Experimental configuration 
on at least $3 \mathrm{~h}$ before testing in order to ensure its internal temperature to be stabilized. The calibration of camera detectors was performed with a black body using a Non-Uniformity Correction (NUC) procedure. The variation in mean temperature change of the tested specimen was defined with respect to the reference sample. A spatial averaging over the central zone of the specimen enabled us to improve the thermal measurement resolution.

Tests were conducted with a home-made biaxial testing machine. Four independent RCP4-RA6C-I-56P-4-300-P3-M (IAI) electrical actuators enabled us to stretch symmetrically the samples. They were driven by a PCON CA 56P I PLP 20 controller and four PCON-CA (IAI) controller position coupled to a homemade LabView program. The cell load capacity was $1094 \mathrm{~N}$. In the present case, the testing machine was used to stretch the precut sample with two actuators, i.e. with a neutral point in the specimen's middle, which enabled us to avoid complex displacement compensation processing.

\subsection{Results}

Figure 12.2 shows the mean temperature change as a function of time for both specimens. In both cases, buckling occurred upon unloading in the second block of cycles. Zones corresponding to buckling are highlighted by black rectangles in the graphs. The times corresponding to maximum stretching are indicated by vertical solid lines. Distinct responses are clearly observed. For material L1, temperature was decreasing during the loading phases, and was increasing during the unloading phases. This response is typical of materials featuring an isentropic coupling. An opposite behavior is observed for material L2, which thus features an entropic coupling. Mechanical dissipation can also be detected from these curves. Indeed for both materials, temperatures was globally increasing over the cycles (positive temperature changes), meaning that the total heat produced by the material over the cycles was positive. In other words, the heat produced is higher that the heat absorbed over one mechanical cycle. The next paragraph provides an analysis in terms of heat source variation.

As indicated in the introduction section, the $0 \mathrm{D}$ approach was applied to calculate the heat sources in relation to the measured temperatures. Equation (12.1) provides the relation between the heat source $s$ (in $\mathrm{W} / \mathrm{m}^{3}$ ) and the mean temperature change $\theta$ :

$$
s=\rho C\left(\frac{\mathrm{d} \theta}{\mathrm{d} t}+\frac{\theta}{\tau}\right)
$$
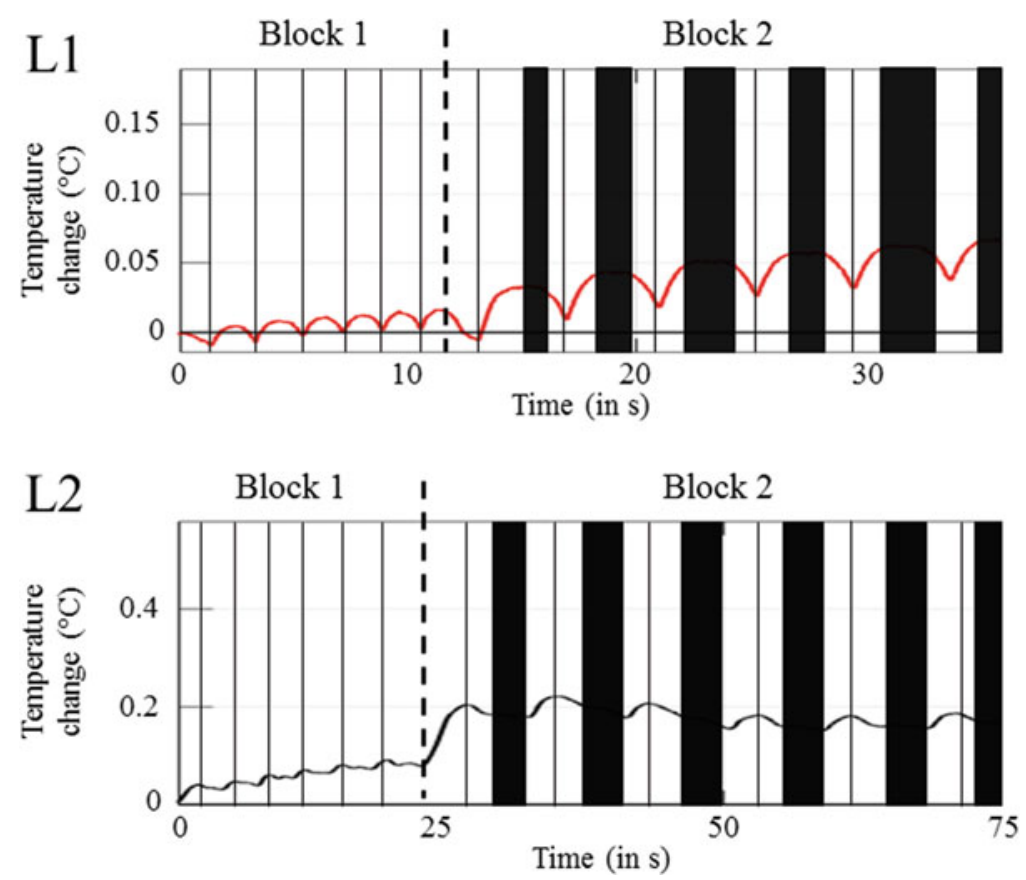

Fig. 12.2 Mean temperature change as a function of time for both specimens. Periods for which specimen buckling occurred are highlighted by black rectangles. The times corresponding to maximum stretching are indicated by vertical solid lines 

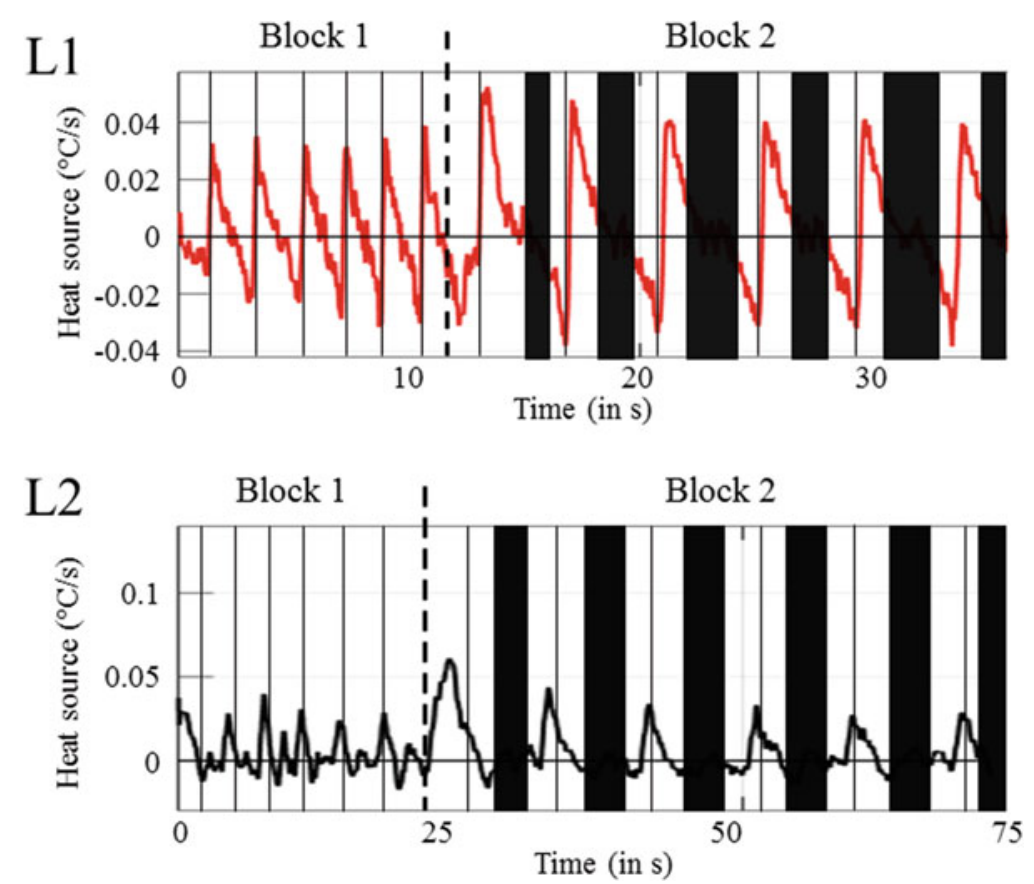

Fig. 12.3 Heat sources as a function of time for both specimens. Periods for which specimen buckling occurred are highlighted by black rectangles. The times corresponding to maximum stretching are indicated by vertical solid lines

where $\rho$ is the material density, $C$ the specific heat and $\tau$ a time constant characterizing the global heat exchanges with the outside of the specimen. The value of $\tau$ was preliminary measured for each specimen by considering a natural return to ambient temperature. By dividing Eq. (12.1) by $\rho C$, it comes

$$
s^{\prime}=\frac{\mathrm{d} \theta}{\mathrm{d} t}+\frac{\theta}{\tau}
$$

where

$$
s^{\prime}=\frac{s}{\rho C}
$$

which can be still named "heat source", but then expressed in ${ }^{\circ} \mathrm{C} / \mathrm{s}$. It corresponds to the temperature rate that would be obtained in adiabatic conditions. Figure 12.3 shows the heat source as a function of time for both specimens. For material L1, heat sources are positive during the loading phases, and negative during the unloading phases, due to an isentropic coupling. Opposite signs are observed for material L2, as expected for an entropic coupling. By temporal integration over each cycle, it can be shown that the total produced heat is positive. As the heat due to the thermoelastic couplings is null aver a cycle, it means that both materials produced mechanical dissipation.

\subsection{Conclusion}

Two leathers were tested under uniaxial cyclic loading while temperature changes were measured at the specimens' surface by using IR thermography. By calculating the heat sources at the origin of the temperature changes, the nature of the thermoelastic coupling was identified. Intrinsic dissipation caused by the mechanical irreversibility was also detected. This type of results could be used to propose accurate thermomechanical behavior laws of leathers. 
Acknowledgements The authors thank the Campus des Metiers et des Qualifications "Design, Materiaux \& Innovation" for supporting this work. The authors also thank the National Center for Scientific Research (MRCT-CNRS and MI-CNRS), Rennes Metropole and Region Bretagne for financially supporting this work. Finally, the authors thank Dr Mathieu Miroir, Dr Eric Robin, Mr Vincent Burgaud and Mr Mickael Lefur for having designed the biaxial tensile machine.

\section{References}

1. Mitton, R.G.: Mechanical properties of leather fibres. J. Int. Soc. Leather Trades Chem. 29, 169-194 (1945)

2. Mitton, R.G.: Tensile properties and their variability in chrome-tanned calfskin. J. Soc. Leather Trades Chem. 32, 310-323 (1948)

3. Lin, J., Hayhurst, D.R., Howard, I.C., Reedman, D.C.: Modeling of the performance of leather in a uniaxial shoe-last simulator. J. Strain Anal. Eng. Des. 27, 187-196 (1992)

4. Makho K.: The effect of different parameters on the rupture properties of leather in a tensile test, Master thesis, Faculty of Science, Physics and Electronics, Rhodes University (South Africa) (1998)

5. Manich, A.M., de Castellar, M.D., Gonzalez, B., Ussman, M.H., Marsal, A.: Influence of leather stretching to gain area yield on its stressrelaxation behavior. J. Appl. Polym. Sci. 102, 6000-6008 (2006)

6. Bison, P.G., Grinzato, E., Marinetti, S.: Leather characterisation by IR thermography. In: Peacock, G.R., Burleigh, D.D., Miles, J.J. (eds.) Proceedings of the Society of the Photo-Optical Instrumentation Engineers (SPIE), vol. 5782, pp. 359-370. SPIE-Int Soc Optical Engineering, Bellingham, WA, USA (2005)

7. Luong, M.P.: Evaluation of the limit of acceptable damage for leather products using infrared thermography. In: Baaklini, G.Y., Lebowitz, C.A., Boltz, E.S. (eds.) Nondestructive Evaluation of Aging Materials and Composites III, Proc. SPIE, vol. 3585, pp. 84-95. SPIE-Int Soc Optical Engineering, Bellingham, WA, USA (1999)

8. Luong, M.P.: Evaluating a limit of acceptable damage for leather products. In: Ellyin, F., Provan, J.W. (eds.) Progress in Mechanical Behavior of Materials (ICM8), Univ Victoria, Dept Mech Engn, Victoria, Canada, vol. 2, Materials properties, pp. 523-528 (1999)

9. Luong, M.P.: Infrared thermography of damage evaluation in leather products. In: Melker, A.I. (ed.) Proceedings of the Society of the PhotoOptical Instrumentation Engineers (SPIE), vol. 3687, pp. 191-200. SPIE-Int Soc Optical Engineering, Bellingham, WA, USA (1999)

10. Chrysochoos, A., Dupré, J.C.: Experimental analysis of thermomechanical coupling by infra-red thermography. In: Boehler, J.P., Khan, J.P. (eds.) Anisotropy and localization of plastic deformation, pp. 540-543. Springer, Dordrecht (1991)

11. Meyer, K.H., Ferri, C.: Sur l'élasticité du caoutchouc. Helv. Chim. Acta. 18, 570-589 (1935)

12. Treloar, L.R.G.: The elasticity and related properties of rubbers. Rep. Prog. Phys. 36, 755-826 (1973)

13. Chadwick, P.: Thermo-mechanics of rubberlike materials. Philos. Trans. Royal Soc. A Math. Phys. Eng. Sci. 276, 371-403 (1974)

14. Chrysochoos, A.: Analyse du comportement des matériaux par thermographie infrarouge. In: Berthaud, Y. (ed.) Photomécanique 95 , Cachan, France, 14-16 March, 1995, pp. 203-211. Eyrolles, Paris (1995)

15. Chrysochoos, A., Louche, H.: An infrared image processing to analyse the calorific effects accompanying strain localization. Int. J. Eng. Sci. 38, 1759-1788 (2000)

16. Samaca Martinez, J.R., Le Cam, J.B., Balandraud, X., Toussaint, E., Caillard, J.: Mechanisms of deformation in crystallizable natural rubber. Part 1: thermal characterization. Polymer. 54, 2727-2736 (2013)

17. Samaca Martinez, J.R., Le Cam, J.B., Balandraud, X., Toussaint, E., Caillard, J.: Filler effects on the thermomechanical response of stretched rubbers. Polym. Test. 32, 835-841 (2013)

18. Samaca Martinez, J.R., Le Cam, J.B., Balandraud, X., Toussaint, E., Caillard, J.: New elements concerning the Mullins effect: a thermomechanical analysis. Eur. Polym. J. 55, 98-107 (2014)

19. Balandraud, X., Le Cam, J.B.: Some specific features and consequences of the thermal response of rubber under cyclic mechanical loading. Arch. Appl. Mech. 84, 773-788 (2014)

20. Le Cam, J.B., Samaca Martinez, J.R., Balandraud, X., Toussaint, E., Caillard, J.: Thermomechanical analysis of the singular behavior of rubber: entropic elasticity, reinforcement by fillers, strain-induced crystallization and the Mullins effect. Exp. Mech. 55, 771-782 (2015)

21. Le Cam, J.B.: Energy storage due to strain-induced crystallization in natural rubber: the physical origin of the mechanical hysteresis. Polymer. 127, 166-173 (2017)

22. Le Cam, J.B.: Strain-induced crystallization in rubber: a new measurement technique. Strain. 54, e12256 (2018)

23. Chrysochoos, A., Pham, H., Maisonneuve, O.: Energy balance of thermoelastic martensite transformation under stress. Nucl. Eng. Des. 162, $1-12(1996)$

24. Balandraud, X., Ernst, E., Soos, E.: Rheological phenomena in shape memory alloys. Comptes-Rendus de l'Académie des Sciences - Série II Fascicule B Mécanique Physique Astronomie. 327, 33-39 (1999)

25. Balandraud, X., Ernst, E., Soos, E.: Relaxation and creep phenomena in shape memory alloys. Part II: stress relaxation and strain creep during phase transformation. Z. Angew. Math. Phys. 51, 419-448 (2000)

26. Balandraud, X., Ernst, E., Soos, E.: Relaxation and creep phenomena in shape memory alloys. Part I: hysteresis loop and pseudoelastic behavior. Z. Angew. Math. Phys. 51, 171-203 (2000)

27. Bubulinca, C., Balandraud, X., Grédiac, M., Stanciu, S., Abrudeanu, M.: Characterization of the mechanical dissipation in shape-memory alloys during stress-induced phase transformation. J. Mater. Sci. 49, 701-709 (2014)

28. Delobelle, V., Favier, D., Louche, H., Connesson, N.: Determination of local thermophysical properties and heat of transition from thermal fields measurement during drop calorimetric experiment. Exp. Mech. 55, 711-723 (2015)

29. Delpueyo, D., Balandraud, X., Grédiac, M., Stanciu, S., Cimpoesu, N.: A specific device for enhanced measurement of mechanical dissipation in specimens subjected to long-term tensile tests in fatigue. Strain. 54, e12252 (2017)

30. Benaarbia, A., Chrysochoos, A., Robert, G.: Kinetics of stored and dissipated energies associated with cyclic loadings of dry polyamide 6.6 specimens. Polym. Test. 34, 155-167 (2014) 
31. Benaarbia, A., Chrysochoos, A., Robert, G.: Influence of relative humidity and loading frequency on the PA6.6 cyclic thermomechanical behavior: Part I. Mechanical and thermal aspects. Polym. Test. 40, 290-298 (2014)

32. Benaarbia, A., Chrysochoos, A., Robert, G.: Thermomechanical behavior of PA6.6 composites subjected to low cycle fatigue. Composites Part B-Eng. 76, 52-64 (2015)

33. Benaarbia, A., Chrysochoos, A., Robert, G.: Influence of relative humidity and loading frequency on the PA6.6 thermomechanical cyclic behavior: part II. Energy aspects. Polym. Test. 41, 92-98 (2015)

34. Benaarbia, A., Chrysochoos, A., Robert, G.: Fiber orientation effects on heat source distribution in reinforced polyamide 6.6 subjected to low cycle fatigue. J. Eng. Math. 90, 13-36 (2015)

35. P. Jongchansitto, C. Douellou, I. Preechawuttipong, X. Balandraud, Comparison between 0D and 1D approaches for mechanical dissipation measurement during fatigue tests, strain, (submitted 2018)

36. Giancane, S., Chrysochoos, A., Dattoma, V., Wattrisse, B.: Deformation and dissipated energies for high cycle fatigue of 2024-T3 aluminium alloy. Theorerical Appl. Fracture Mech. 52, 117-121 (2009)

37. Boulanger, T., Chrysochoos, A., Mabru, C., Galtier, A.: Calorimetric analysis of dissipative and thermoelastic effects associated with the fatigue behavior of steels. Int. J. Fatigue. 26, 221-229 (2004)

38. Wang, X.G., Crupi, V., Jiang, C., Feng, E.S., Guglielmino, E., Wang, C.S.: Energy-based approach for fatigue life prediction of pure copper. Int. J. Fatigue. 104, 243-250 (2017) 